\title{
Strategi Komunikasi Pemasaran Coffee Broker dalam Meningkatkan Jumlah Pelanggan
}

\author{
Bunga Febriana, Yugih Setyanto, \\ bunga.915150201@stu.untar.ac.id danyugihs@untar.ac.id \\ Fakultas Ilmu Komunikasi Universitas Tarumanagara
}

\begin{abstract}
With a lot of business competition in Indonesia, many entrepreneurs have to think about the importance of marketing communication strategies in marketing their products and services. Coffee Broker is a coffee shop that provides various kinds of coffee that can be enjoyed by the community. However, with the many coffee shops in Indonesia, the right strategy is needed to increase the number of customers. Therefore, Coffee Broker have implemented several strategies in promoting and introducing their products to the public. The purpose of this study is to find out the marketing communication strategy that Coffee Brokers do in increasing the number of customers. This study uses qualitative methods by collecting data through interviews, participant observation, and documentation. The results of this study use several marketing communication mixes including advertising, sales promotion, public relations, personal sales and Word of Mouth as elements to support marketing communications of coffee brokers. The Marketing Communication Strategy applied by Coffee Broker shows success because there is an increase in the number of customers in the Coffee Broker.
\end{abstract}

Keywords: Marketing Communication Strategy, Coffee Broker, Marketing Communication Mix, Word of Mouth.

\begin{abstract}
Abstrak
Dengan banyak nya persaingan bisnis di Indonesia, banyak pebisnis yang harus memikirkan pentingnya strategi komunikasi pemasaran dalam memasarkan produk dan jasa nya. Coffee Broker adalah kedai kopi yang menyediakan macam-macam kopi yang dapat dinikmati masyarakat. Namun, dengan banyaknya Coffee Shop di Indonesia, dibutuhkan strategi yang tepat dalam upaya nya meningkatkan jumlah pelanggan. Oleh karena itu, Coffee Broker telah menerapkan beberapa strategi dalam mempromosikan dan mengenalkan produk nya kepada masyarakat. Tujuan penelitian ini adalah untuk mengetahui strategi komunikasi pemasaran yang dilakukan Coffee Broker dalam meningkatkan jumlah pelanggan. Penelitian ini menggunakan metode kualitatif dengan mengumpulkan data melalui wawancara, observasi partisipan, dan dokumentasi. Hasil penelitian ini menggunakan beberapa bauran komunikasi pemasaran yang diantaranya Iklan, Promosi Penjualan, Hubungan Masyarakat, Penjualan Personal serta Word of Mouth sebagai elemen penunjang komunikasi pemasaran Coffee Broker. Strategi Komunikasi Pemasaran yang diaplikasikan Coffee Broker menunjukkan keberhasilan karena terdapat peningkatan jumlah pelanggan di Coffee Broker.
\end{abstract}

Kata Kunci: Strategi Komunikasi Pemasaran, Coffee Broker, Bauran Komunikasi pemasaran, Word of Mouth. 


\section{Pendahuluan}

Di era modern seperti sekarang ini, masyarakat di dorong untuk memenuhi kebutuhan hidupnya. Maka dari itu banyak masyarakat yang berlomba-lomba untuk membuat usaha bisnis, terlihat berbagai usaha perdagangan atau penjualan yang sangat beragam turut serta meramaikan dunia bisnis. Di Indonesia kini yang sedang terjadi adalah maraknya kedai kopi atau Coffee Shop yang menyediakan kopi dari seluruh kota di Indonesia yang dapat di nikmati pecinta kopi seperti Coffee Broker. Dengan banyaknya Coffee Shop di Indonesia, penjual dituntut untuk menjual dagangannya dengan strategi pemasaran yang berbeda-beda.

Dengan meningkatnya perkembangan industri kopi di Indonesia, banyak Coffee Shop yang menerapkan ciri khasnya masing-masing. Hal ini menjadi incaran bagi masyarakat dikarenakan rata-rata Coffee Shop selain menyediakan minuman berupa kopi dan makanan pendamping, mereka juga menyediakan koneksi wi-fi yang dapat diakses oleh pelanggan secara gratis.

Kini terdapat banyak Coffee Shop yang menggunakan konsep dan ciri khas masing-masing demi kepuasan dan menarik hati pelanggan. Begitu juga dengan Coffee Broker yang tidak hanya menjual minuman kopi, namun mereka juga menjual suasana yang dihasilkan dari tempat itu sendiri. Coffee Broker menampilkan suasana yang bertema taman sederhana dengan penerangan lampu kuning yang disusun sedemikian nyaman dengan lantunan lagu yang nyaman di telinga, koneksi wi-fi gratis, Charging Spot, Smoking Area dengan tiupan angin sore ataupun malam hari dan NonSmoking Area dengan AC, dan service dari barista dan pelayan yang sangat baik dengan jam tutup hingga tengah malam sehingga pelanggan tidak terganggu dengan tutup nya toko apabila masih ingin berbincang. Hal tersebut sangat dibutuhkan untuk kenyamanan pelanggan.

Menurut Kotler dan Amstrong (2012:93), "Marketing as the process by which companies create value for customer and build strong customer relationship in order to capture value from customer in return", hal ini menyatakan bahwa pemasaran sebagai proses dimana perusahaan menciptakan nilai bagi pelanggan dan membangun hubungan pelanggan yang kuat untuk menangkap nilai dari pelanggan sebagai imbalan.

Pemasaran merupakan salah satu inti yang membuat bisnis tersebut berkembang, hal ini perlu diperhatikan karena guna berhasilnya upaya penjualan, perlu diadakan strategi komunikasi pemasaran. Karena hal tersebut berperan penting dalam penyampaian tujuan pemasaran suatu produk.

Menurut Kusniadji (2016) dalam Jurnal Komunikasi. Strategi Komunikasi Pemasaran Dalam Kegiatan Pemasaran Produk Customer Goods (studi kasus pada PT Expand Berlian Mulia di Semarang), Vol. 8, No.1, Hal 83-98, Komunikasi Pemasaran merupakan kegiatan komunikasi yang bertujuan untuk menyampaikan pesan kepada konsumen dengan menggunakan berbagai media, dengan harapan agar komunikasi dapat menghasilkan tiga tahap perubahan, yaitu perubahan pengetahuan, perubahan sikap dan perubahan tindakan yang dikehendaki.

Dalam mempertahankan dan meningkatkan jumlah pelanggan, pemilik bisnis harus mengetahui bahwa bukan hanya komunikasi antara pemilik bisnis dan pelanggan, namun juga harus diketahui bagaimana cara mempengaruhi pelanggan serta keinginan, kebutuhan dan kenyamanan pelanggan. 
Dari latar belakang yang telah dirangkum peneliti, peneliti tertarik untuk melakukan penelitian mengenai "Strategi Komunikasi Pemasaran Coffee Broker dalam Meningkatkan Jumlah Pelanggan", karena Coffee Broker merupakan Coffee Shop di Bekasi yang tutup hingga tengah malam setiap harinya dengan mengusung tema garden. Coffee Broker tidak hanya menjual minuman kopi, tapi juga menjual biji kopi. Setelah berkali-kali penulis berkunjung ke Coffee Broker, tempat ini jarang sekali sepi pengunjung, sehingga terkadang perlu menambahkan kursi dan meja tambahan untuk nongkrong di Coffee Broker.

\section{Metode Penelitian}

Pada dasarnya, penelitian ini ditujukan untuk mengetahui strategi komunikasi pemasaran Coffee Broker yang berisikan tentang data, gambar dan sebuah analisis tentang Coffee Broker. Maka dari itu, peneliti memutuskan untuk memilih metode kualitatif sebagai pendekatan penelitian ini.

Penelitian kualitatif menurut Anggito dan Setiawan (2018) menyimpulkan bahwa:

Penelitian kualitatif adalah pengumpulan data pada suatu latar alamiah dengan maksud menafsirkan fenomena yang terjadi dimana peneliti adalah sebagai instrument kunsi; pengambilan sampel sumber data dilakukan secara purposive dan snowbaal, teknik pengumpulan dengan trianggulasi (gabungan), analisis data bersifat induktif atau kualitatif, dan hasil penelitian kualitatif lebih menekankan makna dari pada generalisasi.

Jenis penelitian dengan metode kualitatif yang digunakan penulis bersifat deskriptif. Hal ini dapat menuntun penulis untuk mengekspolarasi dan dapat menganalisis situasi sosial yang diteliti secara menyeluruh, luas dan mendalam. (Sugiyono (2016).

Dalam penelitian ini, terdapat dua jenis pengumpulan data, yaitu sumber data primer dan sekunder. Menurut Sugiyono (2016:225), sumber data primer adalah data yang didapatkan langsung kepada pengumpul data, sedangkan data sekunder adalah data yang didapatkan secara tidak langsung misalnya lewat orang lain atau dokumen dan lain sebagainya. Berikut adalah metode pengumpulan data yang akan dilakukan peneliti:

\section{Wawancara}

Wawancara merupakan suatu teknik pengumpulan data dalam penelitian dengan cara bertatap muka (face to face) atau lewat telepon terhadap orang yang akan di wawancara guna mendapatkan informasi langsung dan jelas yang akan dimasukan kedalam penelitian. Menurut Sugiyono (2016) wawancara digunakan untuk mengetahui atau menemui permasalahan yang diteliti dan untuk mengetahui hal-hal dari responden yang mendalam. Dalam penelitian ini, penulis akan mewawancara Biyu sebagai owner Coffee Broker, Dion sebagai barista, dan Yoga sebagai pelayan, dan Savannah sebagai pelanggan di Coffee Broker. 


\section{Observasi}

Dalam penelitian, diharuskan adanya observasi yang dilakukan oleh peneliti, menurut Supardi (2006) dalam Fitrah dan Luthfiyah (2017) metode observasi yaitu sebuah metode dalam pengumpulan yang dilakukan peneliti untuk mengamati serta mencatat sesuatu yang diselidiki atau diteliti. Dalam penelitian ini, peneliti melakukan observasi langsung yang dilakukan di Coffee Broker, yang bisa juga disebut Observasi Partisipan.

\section{Observasi Partisipan}

Menurut Hariwijaya (2017) observasi partisipan merupakan aktivitas yang dilakukan peneliti untuk dapat terjun langsung berpartisipasi dalam penelitian itu sendiri. Hal ini dilakukan peneliti untuk mendapatkan sumber informasi langsung dari owner Coffee Broker sehingga penulis dapat menganalisa strategi komunikasi pemasaran Coffee Broker dalam meningkatkan jumlah pelanggan secara langsung.

\section{Dokumentasi}

Menurut Kristanto (2018) metode dokumentasi dilakukan peneliti untuk mengumpulkan dokumen-dokumen sehingga data yang diteliti dapat diperoleh. Dokumentasi yang dilakukan peneliti adalah mengambil data jumlah pelanggan Coffee Broker dan mengambil foto tempat Coffee Broker.

Dalam penelitian ini, peneliti menggunakan triangulasi sebagai teknik dalam mengumpulkan data. Menurut Endraswara (2006), langkah - langkah triangulasi dijabarkan sebagai berikut:

1. Triangulasi sumber data, yang dilakukan dengan cara mencari data dari banyak sumber informan, seperti orang yang terlibat langsung dalam objek penelitian.

2. Triangulasi pengumpul data.

3. Triangulasi metode yang dilakukan dengan cara mengumpulkan data melalui macam-macam metode pengumpulan data seperti wawancara, observasi, dan dokumentasi).

Teknik triangulasi diharapkan dapat membantu peneliti untuk mendapatkan sumber data yang kredibel guna menyelesaikan penelitian strategi komunikasi pemasaran Coffee Broker dalam meningkatkan jumlah pelanggan.

\section{Hasil Penelitian}

Tujuan peneliti meneliti strategi komunikasi Coffee Broker adalah untuk mengetahui bagaimana cara pemasaran Coffee Broker sehingga dapat bertahan dan meningkatkan jumlah pelanggan dalam waktu yang terbilang cukup singkat yaitu yang dimulai dari tahun 2018 sampai sekarang dengan persaingan coffee shop yang sedang marak saat ini di Bekasi dengan menggunakan teori Word of Mouth untuk meningkatkan jumlah pelanggan.

Menurut Latief (2019:19), Word of Mouth (WOM) merupakan suatu komunikasi pemasaran yang dilakukan dengan cara promosi yang dilakukan satu pelanggan ke pelanggan lain baik melalui lisan, tulisan maupun media elektronik sebagai media pelanggan dengan tujuan untuk bertukar pikiran tentang pengalaman, pengetahuan serta kesan sebuah perusahaan, produk atau jasa. Dengan menggunakan teori Word of Mouth banyak manfaat yang dapat diambil oleh suatu bisnis khususnya 
Coffee Broker. Salah satunya yaitu pelanggan Coffee Broker yang puas dengan produk yang dijual Coffee Broker secara tidak sadar dapat mempromosikan Coffee Broker ke teman, ataupun ke keluarganya dengan menggunakan komunikasi persuasif. Hal ini menjadi pemasaran yang sangat efektif karena selain Coffee Broker tidak mengeluarkan biaya sama sekali, hal ini juga dapat meningkatkan citra dan nama Coffee Broker sebagai Coffee Shop dengan keunggulannya sendiri. Berikut merupakan hasil yang di dapat peneliti:

Coffee Broker menggunakan bauran Strategi Komunikasi Coffee Broker yang mengusung teori menurut Kotler dan Keller (2019) dalam https://www.esaunggul.ac.id/komunikasi-pemasaran-sebagai-strategi-memperluaspasar/

a. Iklan. Coffee Broker menggunakan iklan di media sosial Instagram untuk membantu mereka dalam menemukan strategi yang efektif. Coffee Broker berperan sebagai peran kunci pemasaran yang menyediakan iklan yang mudah untuk ditangkap oleh pelanggan dimanapun dan kapanpun. (Kotler, Kertajaya, Setiawan).

b. Promosi Penjualan. Coffee Broker melakukan promosi-promosi seperti penawaran diskon, mengadakan event untuk mempromosikan Coffee Broker itu sendiri. Hal ini menjadi promosi yang cukup efektif untuk Coffee Broker karena dengan hal ini Coffee Broker melakukan pengenalan produk dan memberikan kesan kepada konsumen sehingga Coffee Broker mengalami peningkatan pelanggan.

c. Hubungan Masyarakat. Pegawai Coffee Broker merangkap untuk menampung aspirasi atau pesan dari pelanggan dan Coffee Broker selalu berusaha untuk meningkatkan pelayanan sehingga pelanggan mendapatkan apa yang mereka harapkan. Maka dari itu, penting bagi Coffee Broker untuk menjalin hubungan baik agar pelanggan juga tidak sungkan untuk mengaspirasikan pendapatnya yang nanti nya dapat di evaluasi guna peningkatan kualitas dan pelayanan Coffee Broker.

d. Penjualan Personal. Menurut Morissan (2010), penjualan personal adalah suatu bentuk komunikasi secara langsung antara seorang penjual dan pembelinya. Promosi personal dibutuhkan dalam bisnis demi terjadinya komunikasi yang baik antar Coffee Shop dan pelanggan. Coffee Broker memastikan bahwa karyawan nya memberikan pelayanan terbaik untuk pelanggan nya. karena dalam penjualan personal, dibutuhkan 2 pihak yaitu dimana Coffee Broker dan pelanggan berinteraksi. Pihak Coffee Broker dituntut untuk selalu ramah kepada pelanggan nya. Hal ini dilakukan agar pesan dari pelanggan tersampaikan secara jelas kepada pihak Coffee Broker sehingga Coffee Broker dapat membuat kopi yang diharapkan pelanggan nya. sehingga strategi penjualan ini menjadi sesuatu yang efektif.

e. Word of Mouth sebagai Elemen dalam Meningkatkan Jumlah Pelanggan Coffee Broker. Dapat disimpulkan bahwa Coffee Broker yang menggunakan strategi komunikasi pemasaran dari mulut ke mulut (Word of Mouth) menjadi sangat dibutuhkan. Karena banyak pelanggan yang memberikan tentunya kesan baik kepada calon pelanggan lainnya sehingga Coffee Broker mengalami peningkatan jumlah pelanggan dikarenakan Coffee Broker memiliki jam tutup yang fleksibel. Berdasarkan hasil penelitian, rata-rata pelanggan yang datang ke Coffee Broker dari bulan 
Januari 2019 sampai Mei 2019 adalah 1901 - 2424 pelanggan perbulannya. Berikut adalah banyaknya pelanggan yang datang ke Coffee Broker:

Grafik 1 Jumlah Pelanggan dari bulan Januari sampai Mei 2019

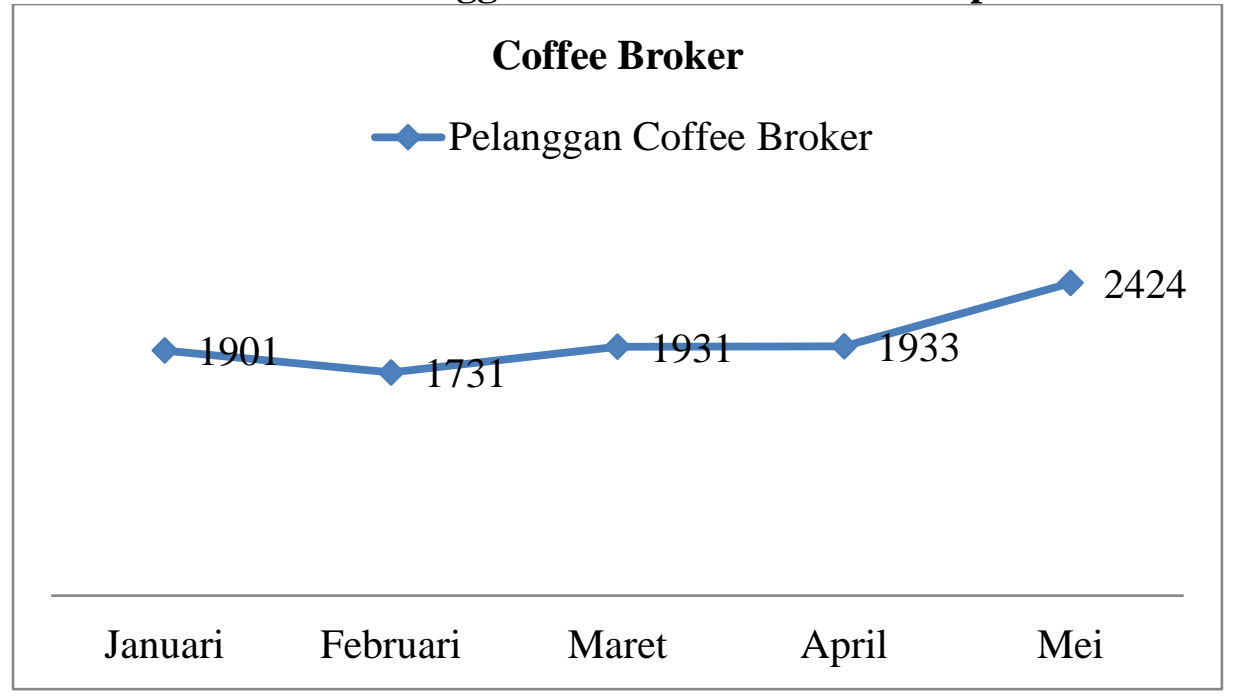

(Sumber: Data dari Coffee Broker)

Berdasarkan data diatas, Coffee Broker menunjukan penurunan dari bulan Januari sampai Februari, namun peningkatan terlihat pada bulan setelahnya, yaitu bulan Maret sampai Mei 2019. Pemasaran dari mulut ke mulut adalah proses pemasaran dari satu orang ke orang yang lain dengan cara rekomendasi pada pihak satu ke pihak dengan tujuan mengekspresikan kesan terhadap barang atau jasa.

Dalam artikel (https://sbm.binus.ac.id/2017/11/21/word-of-mouth-wom/) yang ditulis oleh Rita (2017) yang merangkum buku Sernovitz (2006), terdapat beberapa motivasi terjadinya pemasaran dari mulut ke mulut salah satu nya adalah masyarakat membicarakan suatu produk kepada masyarakat yang lain karena mereka puas dan menyukai produk tersebut, terlebih lagi apabila mereka mendapat pelayanan yang mereka harapkan. Dalam hal ini, dapat dikatakan bahwa Coffee Broker berupaya memberikan pelayanan yang terbaik agar terciptanya citra baik kepada pelanggan guna menarik dan meningkatkan pelanggan yang lebih banyak lagi.

\section{Kesimpulan}

Dalam penelitian ini, peneliti menyimpulkan bahwa Coffee Broker dalam menetapkan Strategi Komunikasi Pemasaran Coffee Broker dalam Meningkatkan Jumlah Pelanggan adalah menggunakan bauran komunikasi pemasaran yang meliputi Iklan, Promosi Penjualan, Hubungan Masyarakat, Pemasaran dari Mulut ke Mulut, dan Penjualan Personal. Dan peneliti menganalisa bahwa strategi pemasaran Coffee Broker yang paling efektif adalah Pemasaran dari Mulut ke Mulut yang bertujuan untuk meningkatkan jumlah pelanggan. Maka dari itu, peneliti mengambil kesimpulan sebagai berikut: Coffee Broker menggunakan bauran komunikasi pemasaran yang diantaranya:

1. Coffee Broker memilih periklanan dengan menggunakan media sosial Instagram, karena sosial media dipercaya dapat membantu bisnis cepat berkembang karena hampir seluruh masyarakat Indonesia menggunakan media sosial. Coffee Broker telah memiliki lebih dari 3000 Followers di 
Bunga Febriana, Yugih Setyanto: Strategi Komunikasi Pemasaran Coffee Broker dalam Meningkatkan Jumlah Pelanggan

Instagram, sehingga pelanggan dapat mendapatkan informasi terbaru tentang Coffee Broker.

2. Promosi penjualan meliputi berbagai event yang diadakan di Coffee Broker dengan tujuan agar banyak masyarakat yang lebih mengenal Coffee Broker dan pada akhirnya dapat menarik pelanggan lebih banyak lagi.

3. Coffee Broker melakukan Hubungan Masyarakat yang bertujuan untuk mengumpulkan aspirasi dan pesan dan komplain pelanggan yang dapat meningkatkan pelayanan serta dapat memotivasi bagi pegawai Coffee Broker.

4. Penjualan Personal yang dilakukan Coffee Broker adalah aktivitas dimana pelanggan berinteraksi dengan pegawai Coffee Broker sehingga pegawai Coffee Broker.

5. Pemasaran dari Mulut ke Mulut, peneliti beranggapan bahwa Coffee Broker menggunakan pemasaran dari mulut ke mulut sangat dibutuhkan dalam meningkatkan jumlah pelanggan. Strategi komunikasi pemasaran Coffee Broker dalam meningkatkan jumlah pelanggan di nilai cukup efektif dilihat dari peningkatan jumlah pelanggan dari bulan Januari sampai Mei 2019.

\section{Ucapan Terimakasih}

Peneliti berterimakasih kepada dosen dan staff Fakultas Ilmu Komunikasi Universitas Tarumanagara yang telah meluangkan waktu dan ilmu nya untuk membantu penelitian ini. Serta keluarga dan teman-teman yang telah memotivasi dan membantu penelitian ini. Dan pihak dari Coffee Broker yang telah meluangkan waktu dan memberikan keterangan serta data demi selesai nya skripsi ini.

\section{Daftar Pustaka}

Anggito, Albi., \& Setiawan, Johan. (2018). Metode Penelitian Kualitatif. Sukabumi: Jejak

Endaswara, Suwardi. (2006). Metode, Teori, Teknik: Penelitian Kebudayaan: Ideologi, Epistomologi, dan Aplikasi. Sleman: Pustaka Widyatama.

Fitrah, Muh.\& Luthfiyah. (2017). Metode Penelitian: Penelitian Kualitatif, Tindakan Kasus \& Studi Kasus. Sukabumi: Jejak

Hariwijaya, M. (2007). Metodologi dan Teknik Penulisan Skripsi, Thesis, dan Disertasi. Yogyakarta: Elmatera.

Jatmiko. (2014). Komunikasi Pemasaran sebagai Strategi Memperluas Pasar. (29 April 2014).https://www.esaunggul.ac.id/komunikasi-pemasaran-sebagai-strategimemperluas-pasar/

Kotler, Phillip and Gary Amstrong. (2012). Prinsip Prinsip Pemasaran. (Edisi 13). Jilid 1. Jakarta: Erlangga.

Kotler, Philip.,Kartajaya, Hermawan. \& Setiawan, Iwan. (2017). Marketing 4.0: Moving from Traditional to Digital. Jakarta: PT. Gramedia Pustaka Utama.

Kristanto, Vigih Hery. (2018). Metode Penelitian: Pedoman Penulisan Karya Tulis Ilmiah (KTI). Yogyakarta: Deepublish.

Kusniadji, Herman. (2016). Strategi Komunikasi Pemasaran Dalam Kegiatan Pemasaran Produk Customer Goods (studi kasus pada PT Expand Berlian Mulia di Semarang), Jurnal Komunikasi Vol. 8, No.1, Hal 83-98. 
Latief, Rusman. (2019). Word of Mouth Communication dalam Penjualan Produk. Surabaya: Media Sahabat Cendikia.

https://sbm.binus.ac.id/2017/11/21/word-of-mouth-wom/ (15 Juni 2019) 